\title{
Titanium elastic nails system (TENS) fixation in midshaft clavicular fractures - A prospective study
}

\author{
Shirish Virupanna Tumbal \\ Associate Professor, Dept. of Orthopaedics, Ashwini Rural Medical College, Hospital \& Research Centre, Kumbhari, Solapur, \\ Maharashtra, India
}

*Corresponding Author: Shirish Virupanna Tumbal

Email: tumbalshirish@yahoo.com

\begin{abstract}
Introduction: The clavicle is most frequently and easily fractured bone, due to direct blow or fall on the outstretched hand. With changing trends in treatment of midshaft clavicle fractures, plating was one of the standard procedure remains for fixation. Recent attracting alternative new technique of fixation is the titanium elastic nailing system (TENS). Due to lacking of prospective studies, the present study was undertaken to assess effectiveness of minimally invasive method TENS for the treatment of midshaft clavicle fracture.

Materials and Methods: The study population included 30 patients exclusively with fracture of midshaft clavicle on plain radiographs from January 2014 to June 2015 at a tertiary care centre. Most of cases were operated within 24-48 hours after trauma. Intra operatively, image intensifier was used for monitoring the manipulations and maneuvering of the nails for closed reductions of the fractures. Patients were followed for 6 months postoperatively and then titanium nails were removed.

Result: Average age of the study population was 35.8 \pm 10 yrs. Most cases were operated within 24-48 hours after trauma. In 24 cases, closed reductions and nailing were done, while in 6 cases, open reductions and nailing were done. Constant score was used to assess the clinical outcome of our patients after union of the fracture. Clinical union was achieved in 3-5 weeks, while radiographic union was achieved in 6-8 weeks. There was no post-operative infection in this study.

Conclusion: Operative interventions with TENS showed better results in regards to early functional recovery. The specific advantages of TENS over plating are that it is minimally invasive, needs lesser operative time, and early mobilization.
\end{abstract}

Keywords: Clavicle fracture, Titanium Elastic Nailing (TENS), Closed reduction, Open reduction.

\section{Introduction}

The clavicle is most frequently and easily fractured bone, due to direct blow or fall on the outstretched hand. Among of all fractures, incidence of clavicle fractures was contributed to $3-5 \% .^{1}$

Various treatment techniques are available for clavicular fractures. ${ }^{1-8}$ An operative approach in trend, which consists of two main procedures namely open reduction \& plating; and by intramedullary nailing through minimal access. ${ }^{1,3,5,8}$ Though plating technique is accepted as a standard technique, it has some disadvantages like large scar, higher non-union rate and difficult application as well as problem with removal. ${ }^{1}$ Whereas, intramedullary nailing of clavicular fractures is done by numerous techniques and multiple devices, ${ }^{2,69-11}$ which have their own advantages and disadvantages. ${ }^{1,6,8,10}$ Nowadays, due to breakage and migration of the plate, rigid fixation is not used..$^{10-12}$

First time a new technique Titanium Elastic Nail Systems (TENS) was presented by Jubel et al and currently it's being advocated though there are different opinions about its uses. ${ }^{13,14}$ Because of less complications, rapid union rate, easy insertion and removal, small scar and lack of breakage, some authors have recommended for its use. ${ }^{6,14}$

Keeping above facts in mind, the present study was undertaken to assess the effectiveness of minimally invasive method Titanium Elastic Nails (TENS) for the treatment of midshaft clavicle fracture.

\section{Materials and Methods}

The present study was conducted from January 2014 to June 2015 at a tertiary care centre. The study population included 30 patients exclusively with fracture of midshaft clavicle on plain radiographs. Titanium Elastic Nails used in this study were comparatively cheaper as compared to plates and affordable to poor patients. Intra operatively image intensifier was used for monitoring the manipulations and maneuvering of the nails for closed reductions of the fractures.

Inclusion Criteria: Clavicular mid-shaft fractures with displacement of fragments more than $2 \mathrm{~cm}$ on plain radiographs, clavicular length shortening more than 2 $\mathrm{cm}$ on plain radiographs, communited fractures, ipsilateral upper extremity injuries / fracture, multiple ipsilateral upper ribs fractures, floating shoulder and fresh closed mid-shaft clavicular fractures.

Exclusion Criteria: Old fractures, open fractures, proximal end and distal end fractures and pediatric age group $(<12 \mathrm{yrs})$.

Technique: Supine position was given on radiolucent table with small bolster beneath the scapula on operating side with $\mathrm{C}$-arm at head end. Incision was made $2 \mathrm{~cm}$ lateral to sternoclavicular joint, and entry was made in the anterior cortex of the bone by a small bone awl. Proper anterior-posterior (AP), caudal \& cranial views were taken throughout the procedure ${ }^{15}$ (Fig. 1). 
"Antegrade flexible intramedullary nailing for fixation of displaced midshaft clavicle fractures"

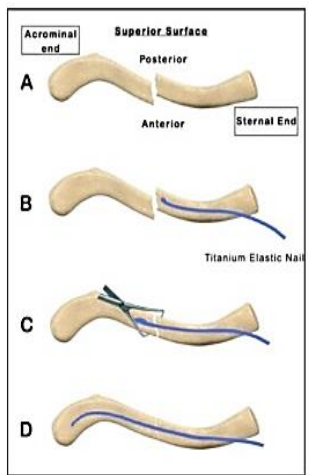

Fig. 1: Antegrade flexible nailing of midshaft clavicle fractures

A size 2-3 mm titanium elastic nail is inserted from medial end and passed through the fracture site and advanced until the tip of the nail was engaged in superolateral cortex of lateral end of clavicle (Fig. 2).

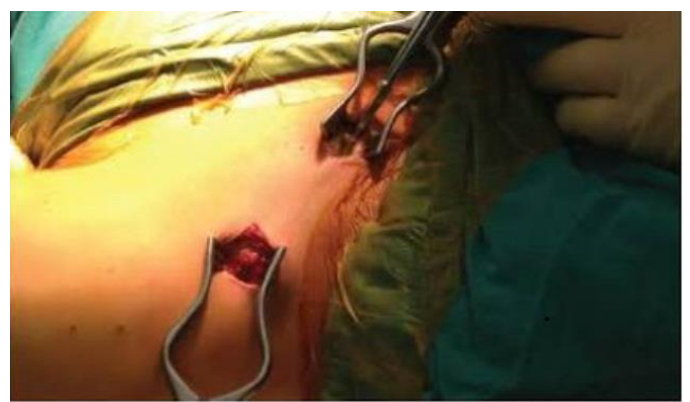

Fig. 2: Entry point

If the medullary canal is very narrow, small hand reamers were used first to ream the canal and then nail was inserted. In few cases, another small incision was made at fracture site and lateral end was reamed to help fracture fixation (Fig. 3).
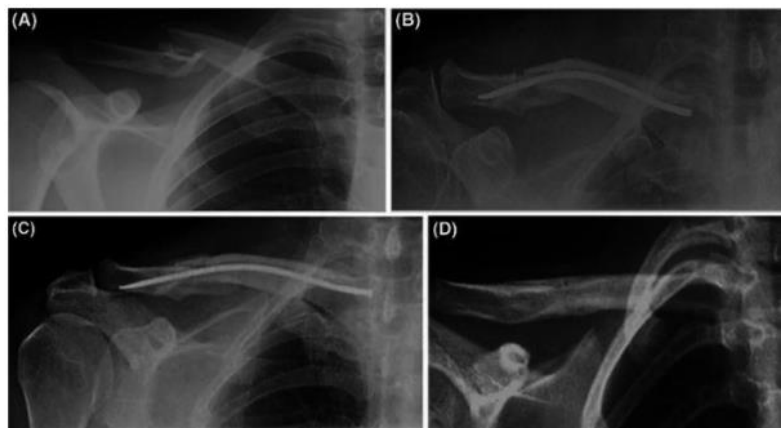

Fig. 3: Intra-operative pictures

Clavicular fracture was protected by standard sling for comfort and pendulum exercises were allowed in the immediate post-operative period. Patients were permitted for free shoulder movement as much as they could during the postoperative period. Sutures were removed on $12^{\text {th }}$ postoperative day and $\mathrm{x}$-rays done at 6 weeks (Fig-4(A) \& 4(B)).
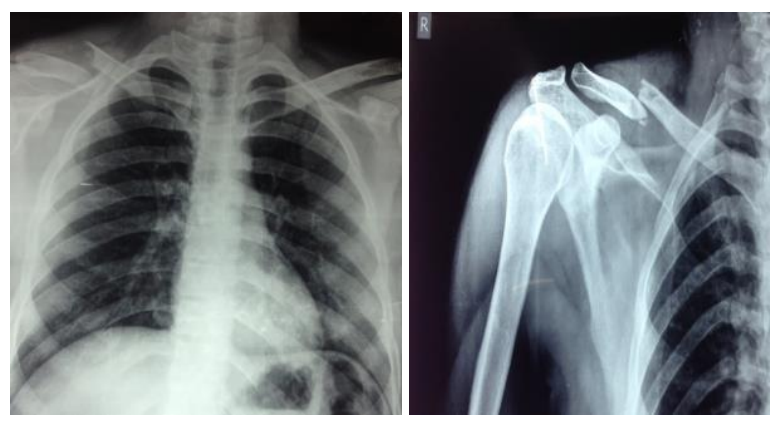

Fig. 4 (a): Pre-operative x-ray

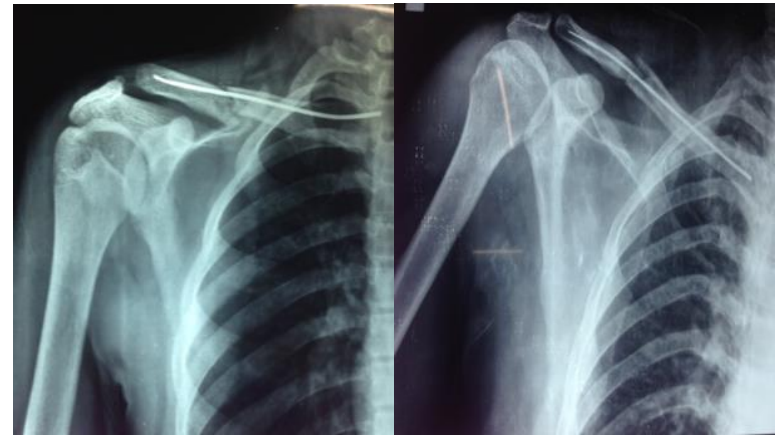

Fig. 4(b): Pre-operative x-ray

Overhead activity was restricted for 3 weeks. After 6 weeks when radiological union was seen, strengthening exercises were started. In this study, all the fractures healed in 6 to 8 weeks postoperatively. Patients were followed for 6 months postoperatively and then titanium nails were removed (Fig. $5 \& 6$ ).

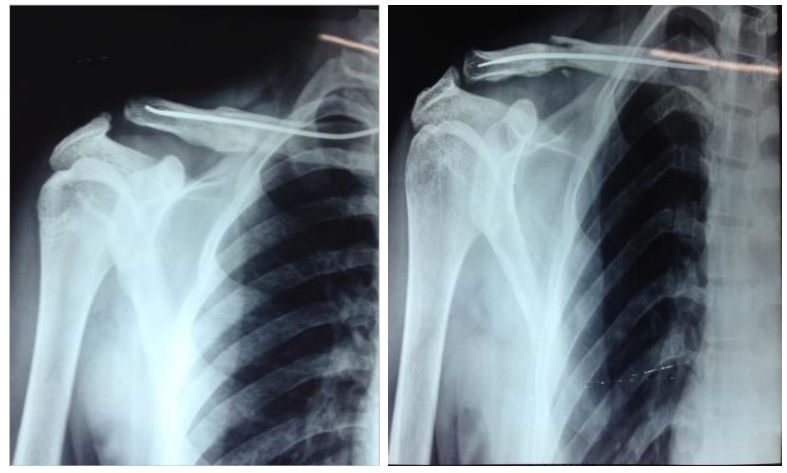

Fig. 5: After six months follow up

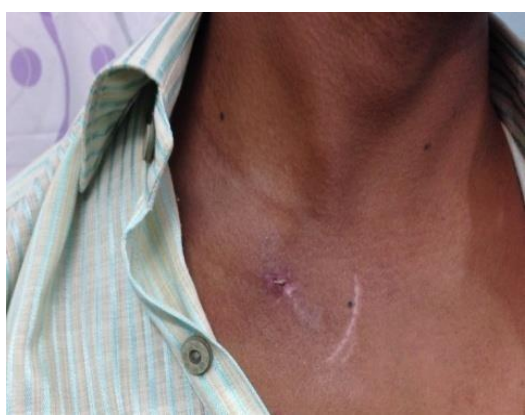

Fig. 6: Small scar at entry point 
Constant shoulder score was used to assess the clinical outcome of our patients. ${ }^{16}$ It contains a questionnaire in which pain, activity level, arm positioning, strength of abduction, forward flexion, lateral elevation, external rotation and internal rotation are measured. The results are based on the score, $>30$ Poor, 21 - 30-Fair, 11 - 20-Good, < 11-Excellent

Statistical Analysis: Descriptive statistics such as mean, SD and percentage was used to present the data. Microsoft excel was used to prepare the tables and graphs.

\section{Results}

Total 30 cases were included, out of which 20 were male and 10 were female patients. Among these, 20 patients had right sided claviclular fractures and 10 patients had left sided fractures. Average age of the study population was $35.8 \pm 10$ yrs. Most cases were operated within 24-48 hours after trauma. In 24 cases, closed reductions and nailing were done, while in 6 cases, open reductions and nailing were done. Titanium Elastic Nails used in this study were comparatively cheaper as compared to plates and affordable to poor patients.

Mid shaft clavicular fractures having displacement less than $2 \mathrm{~cm}$ were excluded from this study and were treated conservatively. Fractures with displacement between $2-5 \mathrm{cms}$ were operated by closed reduction and nailing, while fractures with displacement more than 5 cms were operated by open reduction and nailing.

To assess the clinical outcome of our patients after union of the fracture, constant score was used. Clinical union was achieved in 3-5 weeks, while radiographic union was achieved in 6-8 weeks with average $6.9 \pm 0.9$ weeks. There was no post-operative infection in this study.

Three cases had medial migration of titanium nails at 6 weeks, but callus had already begun to form. There was no case of non-union. Six patients had scars at both the entry points and fracture sites. The remaining 24 patients had about $1 \mathrm{~cm}$ scars only at the entry points.

Table 1: Age distribution

\begin{tabular}{|c|c|c|}
\hline Age group (years) & Number & Percentage \\
\hline $18-25$ & 5 & 16.7 \\
\hline $26-35$ & 11 & 36.7 \\
\hline $36-45$ & 10 & 33.3 \\
\hline $46-55$ & 4 & 13.3 \\
\hline
\end{tabular}

Majority of patients were belongs to the age group 26$35(36.7 \%)$ followed by $36-45(33.3 \%), 18-25(16.7 \%)$ and $46-55(13.3 \%)$.

Table 2: Sex distribution

\begin{tabular}{|l|c|c|}
\hline \multicolumn{1}{|c|}{ Sex } & Number & Percentage \\
\hline Male & 20 & 66.7 \\
\hline Female & 10 & 33.3 \\
\hline
\end{tabular}

Male patients $(66.7 \%)$ were dominant in the study
Table 3: Distribution of side of injury

\begin{tabular}{|l|c|c|}
\hline Side of injury & Number & Percentage \\
\hline Right & 20 & 66.7 \\
\hline Left & 10 & 33.3 \\
\hline
\end{tabular}

Majority of side of injury were found right side $(66.7 \%)$.

Table 4: Distribution of extent of displacement of fractures

\begin{tabular}{|c|c|c|}
\hline $\begin{array}{c}\text { Extent of } \\
\text { displacement of } \\
\text { fracture (cms) }\end{array}$ & Number & Percentage \\
\hline$<2$ & 0 & 0.0 \\
\hline $2-5$ & 24 & 80.0 \\
\hline$>5$ & 6 & 20.0 \\
\hline
\end{tabular}

Most of cases of extent of displacement of fractures were belongs to $2-5 \mathrm{cms}(80 \%)$

\section{Discussion}

Clavicular fractures are very frequent and account for approximately $2.6 \%$ of all fractures, majority of them (80-85\%) occur in the midshafts. ${ }^{17,18}$

OTA (Orthopeadic Trauma Association) classification of midshaft clavicular fractures is as follows: A type - Simple fractures, two fragments, B type - Fractures with a bending wedge, C type Complex fractures.

TENS is a very simple and reliable technique in fixation of displaced midshaft clavicular fractures. Operative time is 25-30 minutes which is less as compared to plating where 55-60 minutes is needed.

The strength of this study is that with minimal invasive technique, midshaft clavicular fractures are fixed by closed nailing or minimal open reduction at fracture site.

The limitations of this study were the need of image intensifier to confirm the position of nail and a radiolucent table.

This method of management of midshaft clavicular fractures has got many advantages over open reduction and plating like minimally invasive technique, less operative time, decreased postoperative morbidity, faster recovery and cosmetically better scar.

The present study shows that management of midshaft clavicular fractures treated by closed nailing is definitely a novel approach. Titanium nails are cheaper as compared to plates and easily affordable to poor patients. TENS would be choice of treatment modality in midshaft clavicular fractures displaced more than 2 $\mathrm{cms}$ and patients requiring early mobilization in form of overhead activity and early return to his normal activities. Overhead activity was started 3 weeks postoperatively. With conservative methods, patients have to wear clavicular braces for minimum of six weeks, delaying rehabilitation programme.

Duan and his colleagues concluded that there were no significant differences of outcomes between plating 
and intramedullary nailing, but plating had a higher complication rate than nailing ${ }^{1}$.

In Muller et $\mathrm{al}^{6}$ study, 31 midshaft clavicular fractures treated by intramedullary nailing with titanium elastic nail system(TENS), found that intramedullary fixation of midshaft clavicle fractures with Titanium elastic nails was a safe, minimally invasive with excellent cosmetic and functional results

Zhang B and his collegues ${ }^{20}$ in 2015 , showed that intramedullary nailing has more advantages as compared to plating with a reduced surgery time, a shorter incision, rapid union time, better shoulder function recovery at 6 months and fewer complications of symptomatic hardware, refracture after hardware removal and hypertrophic scar.

Zehir S and his collegues ${ }^{21}$ in 2015 , concluded that the mean time of operation and mean time of fluoroscopy were significantly shorter in the intramedullary nailing group than those in minimally invasive percutaneous plate osteosynthesis (MIPPO) group. Time of hospital stay and duration for bony union was significantly shorter in the nailing group as compared to MIPPO group.

Comminuted fractures of midshaft clavicle were also treated by TENS. Many times difficult was encounters in negotiating the lateral fragment, so small incision was taken at the fracture site and distal fragment was reamed and then nail (TENS) was passed.

\section{Conclusion}

The specific advantages of TENS over plating are that it is minimally invasive, needs lesser operative time, is cosmetically better and early mobilization. However, with the shorter operative times and better cosmetic appearances, titanium elastic nails are the treatment of choice in displaced midshaft clavicle fractures.

\section{References}

1. Duan X, Zhong G, Cen S, Huang F, Xiang Z. Plating versus intramedullary pin or conservative treatment for midshaft fracture of clavicle: a meta-analysis of randomized controlled trials. J Shoulder Elbow Surg. 2011;20(6):1008-1015.

2. Frigg A, Rillmann P, Perren T, Gerber M, Ryf C. Intramedullary nailing of clavicular midshaft fractures with the titanium elastic nail: problems and complications. Am J Sports Med. 2009;37(2):352-359.

3. Hill JM, McGuire MH, Crosby LA. Closed treatment of displaced middle-third fractures of the clavicle gives poor results. J Bone Joint Surg Br. 1997;79(4):537-539.

4. Khalil A. Intramedullary screw fixation for midshaft fractures of the clavicle. IntOrthop. 2009;33(5):14211424.

5. McKee MD, Pedersen EM, Jones C, Stephen DJ, Kreder $\mathrm{HJ}$, Schemitsch EH, et al. Deficits following nonoperative treatment of displaced midshaft clavicular fractures. $J$ Bone Joint Surg Am. 2006;88(1):35-40.

6. Mueller M, Rangger C, Striepens N, Burger C. Minimally invasive intramedullary nailing of midshaft clavicular fractures using titanium elastic nails. J Trauma. 2008;64(6):1528-1534.

7. Schuind F, Pay-Pay E, Andrianne Y, Donkerwolcke M, Rasquin C, Burny F. External fixation of the clavicle for fracture or non-union in adults. J Bone Joint Surg Am. 1988;70(5):692-695.

8. Zlowodzki M, Zelle BA, Cole PA, Jeray K, McKee MD, Evidence-Based Orthopaedic Trauma Working G.

Treatment of acute midshaft clavicle fractures: systematic review of 2144 fractures: on behalf of the EvidenceBased Orthopaedic Trauma Working Group. J Orthop Trauma. 2005;19(7):504-507.

9. Grassi FA, Tajana MS, D'Angelo F. Management of midclavicular fractures: comparison between nonoperative treatment and open intramedullary fixation in 80 patients. J Trauma.2001;50(6):1096-100.

10. Leppilahti J, Jalovaara P. Migration of Kirschner wires following fixation of the clavicle--a report of 2 cases. Acta Orthop Scand. 1999;70(5):517-519.

11. Lyons FA, Rockwood CA, Jr. Migration of pins used in operations on the shoulder. J Bone Joint Surg Am. 1990;72(8):1262-1267.

12. Naidoo P. Migration of a Kirschner Wire from the clavicle into the abdominal aorta. Arch Emerg Med. 1991;8(4):292-295.

13. Jubel A, Andermahr J, Schiffer G, Tsironis K, Rehm KE. Elastic stable intramedullary nailing of midclavicular fractures with a titanium nail. Clin Orthop Relat Res. 2003;(408):279-285.

14. Kadakia AP, Rambani R, Qamar F, McCoy S, Koch L, Venkateswaran B. Titanium elastic stable intramedullary nailing of displaced midshaft clavicle fractures: A review of 38 cases. Int J Shoulder Surg. 2012;6(3):82-85.

15. Terry Canale S, James H. Campbell, s Operative orthopedics. Philadelphia, Pensylvania: Mosby Elsevier; 2013. 2833 pp. ISBN 0098-7484.

16. Constant CR, Murley AH. A clinical method of functional assessment of the shoulder. Clin Orthop Relat Res.1987;(214):160-164.

17. Robinson CM. Fractures of the clavicle in the adult. Epidemiology and classification. J Bone Joint Surg Br. 1998;80(3):476-84.

18. Craig EV. Fractures of the clavicle. In: Rockwood CA, Matsen FA, editor(s). The Shoulder. 3rd ed. Philadelphia: WB Saunders; 1998. p. 428-82A.

19. Thyagrajan D S, Day M, Dent C, Williams R, Evans R. Treatment of mid shaft clavicle fractures: a comparative study. Int J Shoulder Surg. 2009;3(2):23-27.

20. Zhang B, Zhu Y, Zhang F, Chen W, Tian Y, Zhang Y. Meta-analysis of plate fixation versus intramedullary fixation for the treatment of mid-shaft clavicle fractures. Scand J Trauma Resusc Emerg Med. 2015;23:27.

21. Zehir S, Zehir R, Şahin E. Comparison of novel intramedullary nailing with mini-invasive plating in surgical fixation of displaced midshaft clavicle fractures. Arch Orthop Trauma Surg. 2015;135:339-344.

How to cite this article: Tumbal S V. Titanium elastic nails system (TENS) fixation in midshaft clavicular fractures- A prospective study. Indian J Orthop Surg. 2018;4(4):386-389. 